\title{
Ethical Governance for Emerging ICT: Opening Cognitive Framing and Achieving Reflexivity
}

\author{
Philippe Goujon and Catherine Flick \\ Faculté d'Informatique, Facultés Universitaires Notre-Dame de la Paix, \\ Rue Grandgagnage 21, 5000 Namur, Belgium \\ pgo@info.fundp.ac.be, catherine.flick@fundp.ac.be
}

\begin{abstract}
The impact of techno-scientific developments on societal evolution and lifestyles no longer needs to be demonstrated. The last half of the twentieth century has witnessed a considerable acceleration of the integration of technological elements, Information and Communication Technologies (ICT) into the means of economic production in particular, and social life in general. This article aims to address the methods and practices by which we can effectively open the currently closed cognitive framing of those involved in making ethical governance decisions. This can be done by introducing a second-order reflexivity to allow for accountability and participation in a governance strategy that enables real effectiveness of ethical norm expression in technological projects. This paper draws on the Louvain school of theory of Lenoble and Maesschalk (cf. especially 2006) [10]. The paper's two authors are both involved in the EGAIS ${ }^{1}$ and ETICA ${ }^{2}$ EU FP7 projects where they are further developing and testing out the approach outlined in order to establish an effective ethical governance approach for future European co-financed technology projects.
\end{abstract}

Keywords: Emerging Technologies, Ethics, Governance, Reflexive Governance, Technology.

\section{Introduction}

The rapid change and evolution of ICT presents opportunities for social interaction and the management of life activities in new and often unfamiliar ways. The diversity of use and application areas brought about by the convergence of different media offers great potential for enhancing many aspects of living. At the same time, the main characteristics of these technologies (such as Ambient Intelligence) that lend themselves to inspiring visions of the future also hold the potential for negative ethical impacts. Some ethical difficulties are now familiar to many people, such as challenges to privacy.

Even so it might be hard to identify potential risks in new applications and contexts, especially if we take into account the extent to which new technologies are now

\footnotetext{
${ }^{1}$ http://www.egais-project.eu/

${ }^{2}$ http://www.etica-project.eu/
} 
embedded in everyday human activities. Other risks are less obvious and are likely to become harder to identify since nowadays ICT is becoming "seamless, unobtrusive and invisible" [14]. In other words, the growing process of incorporating ICT into human activities conditions behaviours with processes that are often unconscious or not clearly perceived by the users. This paper uses as its focus, and point of criticism, the many European Commission co-financed projects that concentrate on technological development. The authors are involved in the EGAIS and ETICA projects, which are also co-financed by the European Commission. The aim of the two projects is to explore how to include ethical considerations most effectively in technology-related projects.

\section{Background}

Unfortunately not all projects that are related to technical developments sufficiently integrate the ethical issues that can arise. In particular, the governance ${ }^{3}$ of ethics is often missing, with no guidelines for dealing with ethical issues provided either by the European Union or on a broader international level. Within the European Union, however, the lack of attention paid to ethics has now been recognised: the Seventh Framework Programme (FP7) and to some extent the Sixth Framework Programme $(\text { FP6 })^{4}$ have incorporated some ethical guidelines and ethical support for co-funded projects. These approaches to address ethical challenges vary, but they are often presented as different ways to identify potential ethical issues at some stage in the research project. Further examples of the attention being paid to the importance of ethics in technological projects include the ETHICBOTS ${ }^{5}$, MIAUCE $^{6}$, and SWAMI $^{7}$ projects.

It is insufficient, however, to determine and address the ethical problems raised by ICT from a theoretical perspective if such approaches have no practical impact and remain external to the development of the technical project itself. It is, of course, always possible to analyse a specific technology or area - such as quantum computing, ambient intelligence, or intelligent robots - and determine the ethical issues related to

\footnotetext{
3 The concept of governance is defined by Jessop as "the reflexive self-organization of independent actors involved in complex relations of reciprocal interdependence" [8, p.1]. The most recent developments of the concept, in the context of the European Union, for example, qualify this mode of coordination as democratic, participative and pragmatic, with a focus on supporting collective action (Maesschalck, unpublished, pp. 3-4). According to Jessop, governance is now seen as an "important means to overcome the division between rulers and ruled in representative regimes and to secure the input and commitment of an increasingly wide range of stakeholders in policy formulation and implementation" [8, p.3]. This new governance model requires both groups (rulers and ruled) to engage in a social learning process [12]. Indeed, joined participation in collaborative problem-solving can lead to critical scrutinising of governing variables: goals, values, plans and rules [1].

4 The Framework Programmes are the initiative of the European Union for funding research and technological development. For more information on the current FP (called FP7), see http://cordis.europa.eu/fp7/home_en.html/

${ }^{5}$ ETHICBOTS, http://ethicbots.na.infn.it/

${ }^{6}$ MIAUCE, http://www.miauce.org/

${ }^{7}$ SWAMI, http://is.jrc.ec.europa.eu/pages/TFS/SWAMI.html/
} 
it: however, doing this ignores the foundation of the ethical issues: how, and in what context they were identified and raised, and what conditions are required to address them efficiently. That is to say, we are interested in determining what the conditions for efficient expression of the determined norm (that is, the effectiveness of implementation of a norm in the development of a particular technology) are, in relation to the ethical issues that are raised. If we are looking at the ethical issues of ambient intelligence, for example, different contexts will raise different issues, due to different personal, cultural, social, economic, political, and scientific influences. It also ignores the conditions required to resolve these issues. Instead, it assumes that the mere act of raising the issues provides the solution to them as well.

These presuppositions are common in European Union technical research projects, particularly those which incorporate specific ethical experts, such as MIAUCE and $\mathrm{ACTIBIO}^{8}$. Ethical considerations are, by themselves, insufficient to settle the problem of the relationship between ethics, technologies, and society, above all in the field of ICT and emerging technologies. As a result, the alignment between project development and ethics is far from being achieved. Additionally, the positivist approaches of the social sciences, for example, in their applied "sociology of morals", can reinforce the efficiency of instrumental methods (which are typically those of "social engineering" even if they do not specifically encourage cognitive and normative reflexivity).

The risk is that, by not addressing the institutional, cognitive, and rule conditions for effective integration of those considerations in the context of a technical project, the ethical considerations will be excluded from the technical rationale and treated as a totally separate domain. Ethics is separated from technology in the development process and is ultimately imposed rather than jointly developed. The consequence of this separation is a loss of impact and an undermining of the integral role of ethics in the application of technology.

In this paper, we address the conditions required to identify ethical issues in ICT: particularly concentrating on ethical issue resolution through considering the effectiveness of ethical reflexivity in the technological development process. In this way, the paper does not use a sectoral approach which reduces the debate to the application of a priori accepted principles. Thus, it avoids the problem of the approach becoming a reduced deduction of consequences from the application of such principles to a perceived context. To do this we favour an approach developed by Lenoble and Maesschalck [10] which allows for "opening of the cognitive framing" and "achieving reflexive governance"; hence, the title of our paper. This approach will be discussed later. Many of our examples are of European Union research projects, but the problems and their potential solutions are more generalisable to all technology development.

\section{The Challenges for Ethics in ICT}

In looking at how we can define a new reflective, deliberative, and ethical governance, we will specify a theoretical framework for improved governance mechanisms that identify and address potential ethical issues arising from new and emerging ICT.

${ }^{8}$ ACTIBIO, http://www.actibio.eu/ 
At the same time we remove the separation between ethics and technology, and between the theoretical justificatory approach to determining ethical issues and the application of ethical reflexivity in resolving those issues.

Practically, the main challenge that is investigated in this paper is of a profound lack of background: a strong push for technology development too often obscures the need for any deep ethical consideration that would take place even before a technical project is funded, developed and deployed. Some efforts have, however, begun to consider ethics and ICT in the Ambient Intelligence (AmI) domain that adopt different approaches: analysis from scenarios (e.g. in $\mathrm{PEACH}^{9}$ ), or "ethical review" panels (set up after the project has started, e.g. in MINAmi ${ }^{10}$ ) that consist of "ethical experts" who may come from a completely separate community.

The reflexive articulation of ethical norms and cultural contexts raises many problems, the first of which is the condition of an ethical reflexivity ${ }^{11}$. This challenge is natural, since the researchers and technical developers of ICT systems focus mostly on the technical and economics challenges before them. They not usually aware of potential ethical issues because they see ethical considerations and analysis as an obstacle to either technical or economic development or both.

In short we must first analyse not so much the problem of determining solutions to ethical issues. Rather, we must settle the conditions for raising ethical questions. We must develop a new approach that authorises a real reflexivity which allows for a questioning of the integration of ethics into complex technical systems. The obligations set out by economic constraints, interests concerned with the influence of experts, the general impression of the inevitability of technical projections, social requests, and consumers' needs make it increasingly difficult to define the conditions needed to ensure a critical perspective that can respect the moral autonomy requirements for thought.

We do not mean that existing criticisms do not allow for a certain reflexivity. We argue nevertheless that these criticisms generally show a tendency to restrict ethics to a categorical field. They sacrifice the existence of tension in the name of flattering pragmatism, they are satisfied with ad hoc answers to artificially isolated specific contexts, and they are conditioned or influenced by the reigning instrumental rationality.

The danger is to limit the debate to the scientific perspective alone ${ }^{12}$ and to shun an approach based on technology assessment that debates both the meaning and the ethical, cultural and social challenges. Instead of initiating an inclusive debate on the nature of the different forms of knowledge and vision of world, discussions limit the debate by adopting a positivist and, more often than not, reductionist approach that leads to cognitive closure. Hence how to elicit the cognitive opening-up required for a

\footnotetext{
9 http://www.peachbit.org/

${ }^{10}$ MINami (MIcro-Nano integrated platform for transverse Ambient Intelligence applications, an FP6 project).

${ }^{11}$ Reflexivity may be defined as the capacity of actors and institutions to revise basic normative orientations in response to the evolution of economic, techno-scientific or political systems and to shortcomings in current modes of regulation. This reflexivity is not given, however, as is clearly shown by the growth of science and technology.

${ }^{12}$ Hence the importance of expertise, and the tendency among politicians to favour traditional, "top down" governance of activities in which risks are involved.
} 
genuine reflexivity that would allow us, as Ladrière [9] puts it, to extract the existential and the political meaning from the objective meaning?

The economists' answer appeals to the industrialists, for it confirms their practices and habits. Positivism has become so potent these days that the Enlightenment project of emancipation through reason is, for the most part, either rejected or ignored. In its place appear instructions on how to increase people's power over social processes that have been reduced to the status of objects. Hence again there is a difficulty in controlling the rampant growth of technological innovations politically. Often as not, political institutions make do with a regulatory and financial framework inside a dynamic system that is accompanied by positive feedback that leads to overheating.

In this context, expertise, whether it is philosophical or scientific, becomes the indisputable new source of normativity ${ }^{13}$. The problems revealed are confined to a scientific perspective alone; this means that the challenges taken into account are confined to the realm of strict scientific rationality. Democracy is confiscated. One must be wary of any theory which tries to objectify the world we experience in order to predetermine the form of the world we share. There is a big risk that the possibility of genuine reflexivity will be stifled by a technological and scientific rationality that imposes its value system with, as a result, a dismissal of the prestige of moral reason.

What is at stake is of importance. Various forms of "sectoral ethics" 14 tend increasingly to reinforce the characteristics of social differentiation in modernity by proposing an internal, and specific, framing of moral problems. This risks the exclusion of other external and alternative framings. As a consequence ethics is disconnected from the design of the technological device. The lack of a concrete assessment grid that would outline the embedding of ethics into technological development makes this issue important.

Briefly, the European situation is currently as follows ${ }^{15}$ : some European Commission co-financed ICT projects investigate ethical aspects, but ethical considerations are not included as a "matter of course" in the development cycle. In some cases, ethical experts are brought in at some stage in the project to assess the ethical implications. As a result ethics is often an "add-on", a sort of accessory and instrumentalised guarantee. It is neither properly integrated nor understood in its methods and objectives which are clearly very different from the method and objectives of science and technology.

Consequently, there is a strong need for the inclusion of ethical considerations before, during and at the end of technical and scientific projects, so that the technology "incorporates" and tackles the ethical side (within its whole concept and implementation). The risk is that, by not analysing the conditions (institutional, rules, or cognitive aspects) for the effective integration of those considerations in the context

${ }^{13}$ Normative is contrasted with its antonym, positive, when describing types of theories, beliefs, or statements. A positive statement is a falsifiable statement that attempts to describe ontology. A normative statement, on the other hand, is a statement regarding how things should or ought to be. Such statements are impossible to prove or disprove, thus forever banishing them from the world of the scientific.

${ }^{14}$ By "sectoral ethics" we imply that some forms of ethics are applied to very specific fields or disciplines. Examples could include nanoethics, bioethics, or computer ethics.

15 These observations are intended to relate to European Commission co-funded projects that the ETICA and EGAIS projects is intended to review. 
of a technical project, the ethical considerations will be excluded from the technical rationale and treated as a totally separate domain. The consequence of this separation is a loss of impact, and an undermining of the integral role of ethics in the application of technology. This is quite understandable since the technology can only be limited to the set of its rules (that is, objectivity, and the technical rationality which frames its vision and conception).

Ethics is never the answer (since ethics is always conditional). Rather, ethics is established in this dynamic movement of questioning, before the action and on a border, which separates our subjective existence (with its presuppositions, its preferences, its convictions, its hidden motivations) from the constraining externality (among them, economic, political, hierarchical, technical, and ideological constraints). A moral freedom of positioning is fundamental, since it is open to questioning its possibilities and conditions.

These issues are at the basis of this problem if we desire to take the fundamental changes that affect our world into account. Unfortunately too many projects see ethics as the answer, and thus incorporate technology assessment, value-sensitive design, and other expert-based ethical assessment of technical projects. In reality ethics is the problem.

\section{Limitations of Technology Assessment and Ethical Expertise}

The image of ethics as an answer leads to many "ethics of..." fields in which it is possible to talk about ethics in relation to a particular field. But where do we ultimately arrive? The result is always the same: the analysis of a context from a reconstruction that is limited by the expert's framing and expertise as well as bounded rationality [13], so that a full reconstruction of the context is impossible. Each issue identified and each approach for resolution decided on is characterised by fundamental problems.

All forms of technology assessment processes involve some sort of expert committee designed to give input on the potential impacts of the technology. Many of the more modern forms of technology assessment involve some sort of stakeholder input. They one or more of many tools available to gauge the concern of users, shareholders, or other interest groups. The inclusion of participants from outside the expert community and from the groups that are likely to be affected by the technology is very important not only for the identification of norms, but also the construction of the contexts within the technology. However, the norms constructed by both the experts and the stakeholder participants are in no way required to be ethical norms. In fact they are most likely to be societal norms and expectations of the target groups. Of course some of these may correspond to ethical norms, but there is no definite requirement within technology assessment for the explicit establishment of normative ethical horizons.

The ethical approaches that are used in technology assessment depend greatly on the context. However, it is safe to say that ethical approaches are not usually appealed to as such, even if some provide the underlying motives for carrying out the technology assessment. Consequentialism features highly in traditional technology assessment, such as those identified in 1977: "[Technology assessment] emphasises those consequences that are unintended, indirect, or delayed" [3] or in 1972: "Technology 
assessment is an attempt to establish an early warning system to detect, control, and direct technological changes and developments so as to maximise the public good while minimising the public risks" [2].

Later on, however, more deontological approaches underpinned the ideas for incorporation of the public and other interest groups in the discussions regarding technology and the potential impacts of it on society. Normative technology assessment processes involve a particular focus on assessing technology against moral principles such as beneficence, respect for autonomy, justice, and harm prevention [15]. A virtue ethics-based approach ${ }^{16}$ is rarely found in technology assessment (however implicit), because it relies on assessment of the processes and practices involved in directing technology rather than the technology itself.

In terms of reflexivity, technology assessment processes rarely involve any such process in their own procedures. With each type of technology assessment comes a structured approach that is followed. It often includes the selection of stakeholders and experts, and methods of conducting focus groups.

However, technology assessment could be used as part of a reflexion process within a project, allowing for a learning operation to take place and then the project to adapt to the findings of the reflexion, and to determine the conditions for effective integration of norms into the technology being developed. Real-time technology assessment does attempt to integrate some sort of reflexivity into its approach, by assessing the technology throughout its lifespan of design and implementation. However, this is limited by the primitive nature of early technology and the problem of choice of stakeholders. It is these limitations that really restrict technology assessment to being a tool to incorporate into an overall reflexive approach on a larger view of the technology and its ethical impact on society rather than for it to be used as the point of reflexivity.

Not only do ethical experts generally promote the closure of the cognitive framing, but they actively bring their own biases to shape any participation of the group. As particularly examined by Goven [6], there are two major challenges. First, expert bias is a problematic part of participatory technology assessment approaches. Second, the management of bias may create a sense of scientific unity.

Information sessions run the risk of establishing knowledge hierarchies without allowing participants the time to reflect adequately on the information being passed on. Even after the informing process is over, much of the discussion time is used for further clarification rather than establishing opinion and responses to the technology. This prevents "a thoughtful lay response" [6]. It inhibits the capacity of the actors to understand the issues and context fully: how can the actors have the cognitive capacity to assess the technology to the degree required purely as a result of the teaching and discussion of experts, without questioning the framing and context of the assessment process itself?

A further problem is that "the strategy of managing bias by ensuring the presence of both proponents and opponents [also] resulted in creating the impression of a unified scientific opinion" [6]. A "for or against" polarity is established in the group. The established experts may be unified and enthusiastic about the technology, and those

${ }^{16}$ Virtue ethics was first put forward by Aristotle, and focuses on the moral character of the agent making decisions rather than on the outcomes, procedures, or rules. 
opposed to it may be given much less credibility (they may be accused of rhetoric, or find themselves without an authoritative voice to present their views). Goven concludes [6] that an even-handed approach, with both proponents and opponents present as experts, can still prevent expression of the full range of implications, since these experts could still well be operating within a particular framing (such as occupation, or background from a certain socio-economic status). They may simply serve to give the illusion of diversity while maintaining a closed framing.

Since effective ethical governance requires the opening of the cognitive framing, the problem of expert bias is a tangible one. There may be good will among the experts to properly inform the participants and to engage actively in discussion and democratic deliberation. However, the intrinsic way in which the participatory approaches are set up incite a particular framing for the process which is not subject to adequate reflection. The experts inadvertently end up biasing the forum even if they deliberately try to avoid doing so.

These problems are linked to the conceptions of framing that shape the technology assessment processes. With experts as the source of normativity, and the revealed issues confined to their perspectives, ethics becomes an accessory to the process. There is not proper integration of ethics, and there is an emphasis instead on asserting or justifying the normativity put forward by the experts. This is reflected in some of the analyses of the outcomes of technology assessment processes, which are discussed in the next sections of the paper. There, the agreed resolutions end up having little real effect on the actual trajectory of the project. The differing conceptions of framing also impede the will of those involved in asserting change within the project to actually make changes. Instead they are more likely to minimise the changes the recommendation requires if the framing in which they were made differs from their own.

Thus, technology assessment simply serves the technology: the experts reduce the normative horizon to something of their own construction and use stakeholder input to attempt to justify their decisions, or use stakeholders as guinea pigs to assess the social acceptance of the technology instead of questioning the social acceptability of the technology on the whole. This ultimately renders the form of assessment to a reduction to proceduralism. Although the approach provides a dialogue-based grounding of moral rules and a linking of the individual and community will, it nevertheless relies on a limited context, with a restricted relationship between rational justification of norms and their context of application.

\section{A Critical Perspective}

Every technological artifact is a construction which rests on some a priori rationale (e.g., social, political, or economic). Even if the construction is partially suggested by preliminary information on the behaviour of the objects, it reinterprets this behaviour starting from its own categories. The political impact of a technological artifact cannot thus be assigned to the artifact alone. The impact must be allocated to the techno-speeches which diffuse the technology, give it a specific meaning, and envisage specific uses for it. Data processing and innovations that are related to ICT, even if they seem to be binding on individuals, actually come to satisfy a need and to fulfil 
a function that is largely dependent on the cultural features of the society in which they fit.

It is only from the condition of recognising the non-neutrality of ICT that one can start to change their cognitive framing and can start to consider ethical and societal issues. Without this preparatory step, the world and technology can only be interpreted within the restricted cognitive fields allowed by the framing (in this specific case, the technological framing). The result is to either negate any justification for ethical and societal considerations or to instrumentalise them and consider them as a means to obtain a sort of ethical guarantee and label.

All ethical guidelines share this challenge: they do not take into account the issue of their application, and so, most of the time they have no effect at all. The mechanism which consists of providing an answer expected by a given context (such as an economic or an industrial context) poses ethical questions, since the context itself becomes the justification of the social function of ethics.

This recognition of the non-neutrality of ICT nevertheless returns a realistic ambition of relativising instrumental rationality and aiming at political and societal control, which means also its rehabilitation into the world of social and cultural life. It is certain a priori of intelligibility which guides the technical steps. The immediately urgent issue is to correct the manner of approaching ICT development, particularly the approaches which separate the social approaches from the technological ones, and political approaches from economic and ethical. Too often the accepted responses are only the economic, political and institutional constraints. It is undeniable, for example, that policy-makers are fascinated by technology. Positivism continues to influence our political leaders, who are in a state of utter disarray in relation to the complexity of our world. A symptom of this tendency is the call to use technology in all areas of public policy - such as education, health, environment, administration - to solve the problems which affect our society, and afterwards to use an appeal to ethics to justify the decisions that were already taken (for example, through the use of a European ethical assessment of technical projects).

Thus we need to recognise that the possibility of holding a critical perspective does not mean we can ensure its reality. Indeed, many factors can prevent the effectiveness of its achievement.

\section{Theoretical Consequences for an Ethical Governance}

Every norm aims to institute a way of life that is judged to be rationally more acceptable. The formal rules that condition the rationality of this choice, such as calculation of optimisation, argumentative rules, or any formal mechanism, do not guarantee the transformation of existing ways of life. The achievement of an ideal way of life that is called for by a norm is conditioned by something other than the simple formal validity of the rule.

In reality, the norm can only be expressed by establishing a reflexivity on the perceptions of the ways of life that are lived by and accepted by those to whom the norm is addressed. To suppose that an adaptation of the dominant perception and the corresponding ways of life will happen automatically or will be linked directly to the simple implementation of a formal mechanism that conditions the acceptability of the norm is to misunderstand this reflexivity. 
Proceduralism (i.e., rule-making) is insufficient. It is evident in that the arrangements that are needed in order to organise the reflexive capacity of the actors to identify the various effective possibilities on which the operation of the selection of the norm will be carried out are problematic. Whether a norm is effective in modifying a way of life in a rationally acceptable way presupposes an independence from the discursive procedures that are used to select what is rationally acceptable. All the procedural mechanisms and rational approaches to the determination of a norm cannot by themselves assure the modification of a way of life.

By increasing the capacities for reflexivity with regard to the conditions that relate to the production of the norm, the effectiveness of norm expression could be measured. This measurement could take place according to the incentives needed to enable the reflexive reconstruction undertaken by the actors, and driven by what motivates their attempts to institute a new way of life.

Without the organisation of this common reflexive capacity, and the form of negotiation it involves among the various norms to be constructed, the normative injunction risks remaining insufficient even if the objective is judged relevant and legitimate. The operation of judging the conditions of the choice of the rationally acceptable idealised way of life (that is, the rational determination of the norm that is supposed to enable the achievement of this objective, and the effective transformation of this way of life by the application of the norm) is distinct and asymmetric. Asymmetry is the way in which the social meanings of a norm are conditioned by an operation that cannot be anticipated by formal variables of reasoning (variables that condition the norm's relevance). Therefore every reconstruction of the process that was enacted by the production of a norm itself mobilises two operations which do not respond to the same conditions of production. The intersecting articulation of this asymmetry is the very focus of governance arrangements.

In order to undertake these operations, it is necessary to organise the reflexive capacity of the actors. This has to be done by constructing the capacities of the reflexivity. It should be done in such a way as not to presuppose it as already existing due to a formal method, such as argumentation, deliberation, debate, or discussion. All these formal methods presuppose their own conditions; as such, they do not necessarily involve reflexivity. It is therefore important to make sure that every application of a norm presupposes not only a formal moment of choice about its acceptable normative constraints, but a selection of the possibilities that is made according to the perception of what is an acceptable way of life within the community concerned.

However, without a negotiated construction of the moment of reflexivity that is specific to the conditions for the application of the norm, there will be no control of the process of the expression of the norm. It will be left to the dominant common culture to express it. What is often presented as the only effective choice is always conditioned by an operation of this sort, including the construction of deontological codes (that is, codes of behaviour or codes of practice). Criticism of this reconstruction of the reflexivity used in the construction of the social norm also affects the moral approaches to legitimacy. Economic theories often obliterate the operation of the choice of possibilities that already condition the effects of rational decisions ${ }^{17}$. Yet

${ }^{17}$ This blind point affects the rational choice theory framework. 
deliberative or communicative approaches ${ }^{18}$ also miss the challenge of providing the appropriate conditions to ensure an effective expression of the ethical objectives they intend to promote.

Institutional cooperative arrangements are necessary for the effectiveness of the expression of norms in concrete situations, as well as for the legitimisation process of the norm. These arrangements are a result of the contextual limitation as an inescapable part of the reflexive operator of modality.

The institutional arrangements for this reflexivity have to be established. This is the very aim of the ETICA project. This will help to overcome the fundamental limitations of existing ethical approaches, which ignore the fundamental issue of the moment of the application of the norm.

Determining these arrangements will allow actors and institutions to experience a learning process whenever they are confronted by an ethical issue. They will reflect on the success of the learning process, and reframe the context of the situation in order to establish a norm more effectively within the context. From a more official perspective, this experience will enable us to assess the effectiveness of the result of that process.

\section{Overcoming the Limitations of Current Approaches}

Overcoming these challenges is not simple. Bounded rationality imposes serious constraints on those involved in the ethical analysis of projects; it is one of the constraints that "limit public actors' capacity to adequately diagnose and cure $[\ldots]$ problems" [11]. There is a necessity not only to require co-operation from inside and outside the technological development process, but to require a much fuller cognitive understanding "by bringing actors together from across sectoral, disciplinary, and other divisions of modern life" [11]. Coupled with procedural rationality, "the setting up of mechanisms to promote self-learning within organisations", this approach opens up "dialogue between all the parties concerned by a problem" [5]. It enables a reflexivity between the justification of a rule and the application of the rule within a practical context [4]. Only through opening up dialogue and co-operation among the currently separated ethical and technological groups will we be able to experience the required learning operation. However, opening up discussion is not the only criterion.

In many technological projects, public participation is unlikely to be adequate due to the problems of expertise and pre-existing power structures that are introduced by the participants [11]. Although rule-making (often called "proceduralism") offers some solutions to encouraging the democratic aspects of this process, it is insufficient to account for the internal power-plays and various external influences on such procedures.

Instead, we need to ensure a second-order reflexivity that allows project participants to test the governance process continually for social legitimacy. This enables "continued discussion and proofing through testing of ideas and comparison of results, including raising questions of distributive fairness and overall efficiency" [11], as well as genuine accountability of governance.

${ }^{18}$ Such as the procedural approaches of Habermas [7]. 
The other problem with a Habermasian proceduralist approach [7] is that it assumes that the rational justification of ethical norms (that is, the identification of the norms) brings with it the conditions for the implementation of the norms. The rational justification of a norm cannot, first, be arrived at by a process of consensus or compromise, nor, second, can it be decided by a majority vote by a democratic process. This approach presupposes that those who are to implement the norms have a will to be ethical.

Following in Lenoble and Maesschalck's footsteps [10], we cannot simply accept ethical norms as they are identified. Instead, we need to examine the construction of these norms, taking into account their relationship to the context in which they are to be implemented.

At this stage of our argumentation therefore, we wish to summarise: the main challenges that we have encountered thus far in European technology development projects are as follows:

1. There is a separation between ethical and technological communities

2. Expert and participatory approaches are insufficient by themselves to provide effective and efficient ethical governance procedures

3. There is a separation between the context of application of the norm and the context of the legitimisation of the norm

4. There is a problem with the reflexive relationship between the construction of the norm and the context.

Effective governance arrangements must thus address the construction of contexts and norms, the application of these, and the relationship between the construction of the norm and the context.

Progressive reflexive governance requires a threefold approach. The approach proposes that the actors involved organise themselves in a way that enables them to be reflexive about their own construction of the framing, context, and norms. This approach involves the previously discussed learning process. It requires the actors involved to assess their own framework for the selection of governance practices, so that they can decide whether these practices are appropriate to use. "A form of governance would qualify as reflexive if it favoured the success of the learning operation required to satisfy the normative expectations of participants in a collective action" [10].

The learning operation is particularly required after encountering an external "shock" factor, that is, a problem that has arisen which requires a decision to be made. The decision-making process here requires choosing a real-life solution that is supposed to optimise the ideal objective that is illustrated by the anticipation of an idealised way of life. The involvement of this anticipation of a normative horizon is very important in ensuring that the values involved in the decision are ethical values. This requires, however, that the decision-maker ensures that the possibilities of the context within which the idealised way of life is to be achieved are not exhausted. He or she transforms the context in order to incorporate the new ideal norm brought about by the "shock". Two examples follow. One is the identification of minority interests in a project: how would deaf people use the technology that is being developed in the project? Another example could be identification of the dual-use nature of a particular technology. These sorts of decisions require the participating actors to "learn" and 
shift their framing by transforming the context, so that the construction of the norms and context take these new developments into account.

Lenoble and Maesschalck [10] advocate a contextual pragmatist approach, which requires a self-capacitation on behalf of the actors, allowing the actors to identify and understand how their own identity impacts on the decisions and tools they make and use. This understanding allows the actors to build a representation of themselves, the context, and the relationship between the two. However it is not this relationship between the actors and their own selves, but the relationship between the actor, other actors, and the institutional mechanisms that form the framework within which they interact that is key. These theorists wish to go beyond requiring the actor to have the will to be ethical. They desire an effective expression of ethical norms to take place (and to result in behavioural change). Finally, they advocate a mechanism for "vigilance" which is "designed to assess the extent to which the institutional mechanisms set up by the actors, in interaction with each other, have made it possible [...] to carry out the hoped for adjustments and learning effects" (ibid, [10]). This monitoring process throughout the duration of a technological project would permit a continual assessment of the effectiveness of the governance framework and the capacity of the actors to "commit themselves" to cause ethical change within the project's own trajectory.

This approach satisfies the requirements for ethical governance. It allows for the opening up of cognitive closure, through inclusive participation of actors from across many backgrounds. Yet it also confronts the problem of pre-existing power structures. It continually assesses the capacity for the actors themselves to reflect on their own participation, background, and context so that the effect of these pre-existing structures is minimised. It evaluates the usefulness of the framework and tools within the framework that are being used, and provides an environment in which an external "shock" is efficiently dealt with while preserving the ability to effect ethical change in a technological project.

\section{Conclusions}

This paper addresses the background behind a need for a new governance approach in technological development projects. It establishes the separation between the ethical and technological communities and the limitations of current approaches, and it proposes an approach that escapes the limits of formalism by allowing for genuine second-order reflexivity. It is necessary to construct the framing of the context in relation to the norm, and to open up the context for a feedback mechanism to enable a reflexivity on the opening of the framing.

In order to do this, we have proposed the use of the Louvain school theory of Lenoble and Maesschalck [10]. This school of thought provides a framework in which we can construct a two-way relationship between the norm and the context. Thus, we can overcome the limitations of current governance approaches and achieve a secondorder reflexivity.

This theoretical development is a work-in-progress for the authors in conjunction with the EGAIS and ETICA EU FP7 projects. It is in these projects that we will further develop and test the approach outlined in order to establish an effective ethical governance approach for future technology projects. 


\section{References}

1. Brabant, C.: For a Reflexive Governance of Education: the Example of Home Education in Quebec. In: Proceedings of the European Conference on Educational Research, September 19-21. University of Ghent (2007)

2. Cetron, M.J., Connor, L.W.: A method for planning and assessing technology against relevant national goals in developing countries. In: Cetron, M.J., Bartocha, B. (eds.) The Methodology of Technology Assessment. Gordon and Breach Science Publishers, New York (1972)

3. Coates, J.F.: Aspects of innovation: Public policy issues in telecommunications development. Telecommunications Policy 1(3), 196-206 (1977)

4. De Munck, J., Lenoble, J.: Transformation in the Art of Governance: A Genealogical and Historical Examination of Changes in the Governance of Democratic Societies. In: De Schutter, O., Lebessis, N., Paterson, J. (eds.) Governance in the European Union, pp. 189212. Office for Official Publications of the European Communities, Luxembourg (2001)

5. De Schutter, O.: Proceduralising European Law: Institutional Proposals. In: De Schutter, O., Lebessis, N., Paterson, J. (eds.) Governance in the European Union, pp. 189-212. Office for Official Publications of the European Communities, Luxembourg (2001)

6. Goven, J.: Citizens and Deficits: Problematic Paths toward Participatory Technology Assessment. In: Proceedings of the Summer Academy on Technology Studies 2002, InterUniversity Research Centre for Technology, Work and Culture, October 29, pp. 1-18. University of Klagenfurt (2002)

7. Habermas, J.: The Theory of Communicative Action. Translation: T. McCarthy. Polity, Cambridge (1981/1984)

8. Jessop, B.: Governance and Metagovernance: On Reflexivity, Requisite Variety, and Requisite Irony. Department of Sociology, Lancaster University, Lancaster, UK (2002), http: / / www. lancs.ac.uk/fass/sociology/papers / jessop-governance-and-metagovernance.pdf /

9. Ladrière, J.: Philosophie politique et philosophie analytique. In: Ladrière, J., Van Parijs, P. (eds.) Fondements d'une théorie de la justice. Essais critiques sur la philosophie politique de John Rawls, p. 222. Éditions de l'Institut Supérieur de Philosophie, Louvain-la-Neuve (1984)

10. Lenoble, J., Maesschalck, M.: Beyond Neo-Institutionalist and Pragmatist Approaches to Governance. In: REFGOV working paper, UC Louvain (2006)

11. Overdeest, C.: The Open Method of Coordination. In: New Governance and Learning: Towards a Research Agenda. Working Paper, The New Givernance Project. University of Wisconsin-Madison (2002)

12. Schön, D.A.: The Reflective Practitioner: How Professionals Think in Action. Temple Smith. London (1983)

13. Simon, H.A.: Models of Bounded Rationality. MIT Press, Cambridge (1982)

14. Wright, D. (ed.): Safeguards in a World of Ambient Intelligence (SWAMI). Final Report (2006)

15. Verbeek, P.-P.: Persuasive Technology and Moral Responsibility: Toward an Ethical Framework for Persuasive Technologies. Persuasive 6, 1-15 (2006) 